\title{
Analysis of Correlation between Results of Polysomnography and Obstructive Structure by Drug-Induced Sleep Endoscopy in Obstructive Sleep Apnea Patients
}

\author{
Jang Won Choi, Soo Kweon Koo, Nam Suk Myung, \\ Yang Jae Kim, Gil Hyeon Lee and Hyoung Joo Lee \\ Department of Otorhinolaryngology-Head and Neck Surgery, Busan St. Mary's Medical Center, Busan, Korea
}

\author{
폐쇄성 수면무호흡증 환자에서 수면다원검사 결과와 약물유도수면내시경을 이용해 \\ 관찰된 폐쇄 부위의 연관성에 대한 분석
}

최장원 · 구수권 · 명남숙 · 김양재 · 이길현 · 이형주

부산성모병원 이비인후과

Received January 12,2013

Revised April 21, 2013

Accepted May 1, 2013

Address for correspondence

Hyoung Joo Lee, MD

Department of Otorhinolaryngology-

Head and Neck Surgery,

Busan St. Mary's Medical Center,

538-41 Yongho-dong, Nam-gu,

Busan 608-838, Korea

Tel $+82-51-933-7214$

Fax $+82-51-956-1956$

E-mail hobbangmania@naver.com
Background and Objectives Polysomnography (PSG) is useful for the diagnosis of obstructive sleep apnea (OSA) and the analysis of its occurrence and severity. Nevertheless, physical examination and PSG are not sufficient to localize the obstructed structure before operation. Drug-induced sleep endoscopy (DISE), on the other hand, is expected to provide an accurate diagnosis as it can be used to evaluate the intensity of operative effect and can minimize additional unnecessary procedures. The aim of this study is to analyze correlation between the results of polysomnography and obstructive structure by DISE in OSA Patients.

Subjects and Method This study was conducted on 75 patients, who were diagnosed with OSA by PSG and DISE. Obstruction levels and individual structures were classified by modified VOTE classification. The patients were divided into groups according to the results of PSG and BSI; the correlation between DSI results and each of these groups were analyzed.

Results There were no statistically significant differences in obstruction levels between PSG data and DISE finding. Obese patients, positional-dependent OSA and sleep stage non-dependent OSA (NREM OSA) groups showed more obstruction on the lateral pharyngeal wall. Severe OSA groups showed more obstruction on tonsils. Obese patient groups revealed more obstruction on tongue base, but did not contribute to statistically significant results.

Conclusion In our study, obese patients, severe OSA, positional-dependent OSA and NREM OSA groups tended to exert greater influence on the obstruction of lateral pharyngeal wall. Surgeons should be aware of these findings when performing sleep surgery.

Korean J Otorhinolaryngol-Head Neck Surg 2013;56:346-53

Key Words Drug-induced sleep endoscopy $\cdot$ Obstructive $\cdot$ Polysomnography $\cdot$ Sleep apnea.
서 론

폐쇄성 수면무호흡증(obstructive sleep apnea, OSA)의 진 단은 수면다원검사(polysomnography, PSG)를 통하여 수면
시 호흡이상의 유무와 정도를 평가할 수 있으며 현재 가장 객 관적이고 신뢰성 있는 검사로 인정되고 있다.) 그러나 PSG 결 과에는 OSA에 영향을 미치는 해부학적 요인에 대한 평가가 포 함되어 있지 않기 때문에 OSA 환자에 대한 수술 방법의 선택 
또는 수술 효과의 예측에는 큰 도움이 되지 못하는 제한점이 있다. ${ }^{2-4)}$ 수술 효과와 관련된 문헌들을 살펴보았을 때 OSA 환자에서 수술성공률은 다양하게 보고되고 있다. 이렇게 다 양한 수술성공률은 수술 전에 수술 후 결과를 미리 어느 정도 예측하기가 어렵다라는 의미를 내포하고 있는데, 이러한 이유 는 OSA에 관여하는 다양한 작용 요인들과 함께 수술 전 상 기도의 폐쇄부위를 예측하는 데 도움이 되는 검사들이 보완 되지 않았기 때문으로 생각된다. ${ }^{1-4)}$ 따라서 지금까지 치료의 성공률을 높이기 위해 치료 전에 폐쇄 부위를 예측하기 위한 여러 가지 방법들에 대한 연구가 있어왔다. ${ }^{4)}$ 그 중 OSA 환자 에서 수면상태에서 직접적으로 폐쇄 부위를 관찰하는 수면 내시경(drug-induced sleep endoscope, DISE)은 1991년 Croft와 Pringle ${ }^{5)}$ 에 의해 처음으로 소개되었는데, 약물로 수 면을 유도한 후 굴곡형 비인두내시경을 이용하여 비인강에서 하인두까지의 수면시 상기도를 관찰하는 것으로써, 관찰된 폐 쇄 부위에 따른 적절한 수술적 치료를 선택할 수 있어 수술 의 효과를 높이고 불필요한 술식을 줄일 수 있을 것이라 예상 된다.

이에 저자들은 $\mathrm{PSG}$ 의 결과와 DISE로 관찰된 폐쇄 부위 (obstruction level) 및 각 구조물(obstruction structure)과의 연관성을 평가하여 OSA 환자에 대한 치료 방침 수립 및 치 료 효과 예측에 도움을 얻고자 본 연구를 실시하였다.

\section{대상 및 방법}

2011년 3월부터 2012년 12월까지 코골이 및 수면무호흡증 의 진료를 위해 본원 이비인후과 외래를 방문하여 PSG와 DISE를 시행한 환자를 대상으로 하였다. PSG 및 DISE를 실 시하기 전에 모든 환자에게서 병력 청취와 함께 귀, 코, 목에 대 한 이학적 검사를 시행하였다. 무호흡-저호흡지수(apnea-hypopnea index, AHI) 5 이상으로 OSA로 진단받은 환자 중 18 세 이상이고, 명백한 하악후퇴증, 하악이형성증 등이 있는 극 단적으로 비정상적인 경우를 제외한 환자를 대상으로 하였다. 전신 상태가 좋지 않아 DISE를 시행하기에 위험한 환자, 이 전에 OSA로 수술을 받았거나 치료중인 사람, 비중격이 심한 만곡을 보이는 환자를 제외한 75 명의 환자를 대상으로 분석 을 실시하였다.)

환자 75명의 평균 나이는 42.09세였으며 남자가 63명, 여자 가 12 명이었다. 평균 체질량지수(body mass index, $\mathrm{BMI}$ )는 $25.42 \mathrm{~kg} / \mathrm{m}^{2}$ 이었으며 평균 Epworth Sleepiness Scale은 10.24 로 나타났다. PSG 결과 상 경도의 수면무호흡증 환자는 32 명, 중등도 23 명, 중증 20 명의 분포를 보였다.

\section{표준수면다원검사}

수면다원검사(WEE-1000K, Nihon Kohden, Japan)의 표 준검사항목으로는 뇌파검사, 안전도, 턱과 경골전부의 근전 도, 심전도, 비강 및 구강의 공기 흐름, 흉부 및 복부의 움직임, 동맥혈 산소포화도, 수면시의 자세 등을 검사하였다.

\section{DISE 에 따른 폐쇄 부위 및 구조물에 대한 분류}

$\mathrm{DISE}$ 를 시행하기 전에 기도분비물을 감소시켜 관찰을 용 이하게 하기 위해 정맥으로 항콜린제제(glydopyrrolate $0.2 \mathrm{mg}$, Mobinul)를 투여하고, 환자의 자극을 최소화하기 위하여 일 측 비강에 국소 혈관수축제와 마취제가 혼합된 면구를 삽입 하여 비강 점막을 수축시켰다. DISE를 시행 받은 모든 환자는 마취과 의사의 감시 하에 수술 방에서 midazolam $(0.07 \mathrm{mg} /$ $\mathrm{kg}$ )을 정맥으로 투여하여 수면을 유도한 후 시술받았다. 예 민하거나 술, 항불안제, 진정제 등을 습관적으로 복용하는 환 자의 경우에는 앞에서 언급한 midazolam만으로는 진정이 충 분하지 않을 경우가 많아 $1 \sim 2.5 \mathrm{mg}$ 의 midazolam을 추가로 투여하거나 midazolam 대신 propofol $(1.5 \mathrm{mg} / \mathrm{kg})$ 을 투여하 였다.7) 환자의 자세는 앙와위로 검사를 진행하였고 맥박 산소 측정법(pulse oximetry)과 흥부 양극유도 심전도(three-lead electrocardiography)를 이용하여 마취 중 감시를 시행하였다. 마취 심도는 정상적인 크기의 목소리에 반응이 없는 정도로 설 정하였고 이는 Modified Ramsay Score 5 또는 Observer's Assessment of Alertness/Sedation Score 2 3에 해당하며 이 는 이전의 연구들에서 사용되어 왔다. ${ }^{8)}$

DISE의 임상적으로 널리 사용되고 있는 일관적인 폐쇄 부 위에 대한 분류는 아직 없는 실정이나, 저자들은 현재까지 발 표된 분류법 중 2011년 Kezirian 등9)에 의해 제안된 폐쇄 부 위에 기여하는 특정 구조를 가장 논리적으로 분류되었다고 생 각되는 VOTE classification을 변형하여 사용하였다. 폐쇄 부 위를 기존의 구분방법인 retropalatal/retroglossal 부위(level) 로 나누고 폐쇄 정도는 폐쇄가 없고 떨림이 없는 경우는 0 , $50 \sim 5 \%$ 의 폐쇄를 보이거나 떨림을 보인 경우를 1 , 그 이상을 2 로 정의하였다. Retropalatal 부위는 폐쇄에 기여하는 각 구 조물(structure)의 3차원적 구조를 감안하여 전후 직경이 좁 아지는 연구개, 측부 직경이 좁아지는 인두 측벽, 측부 직경을 좁히지만 독립적인 구조물인 구개 편도, 세 가지로 구분하였 고, retroglossal 부위는 전후 직경이 좁아지는 설근부, 인두 측 벽, 전후 직경을 좁히지만 독립적인 구조물인 후두개로 세분 하였고 위와 같이 폐쇄 정도를 평가하였다(Table 1). 폐쇄에 대한 평가는 주관적인 요인을 배제하기 위해 서로 다른 두 명 의 이비인후과 의사가 독립적으로 평가하여 그 값을 평균하 였다. 
Table 1. Classification of drug-induced sleep endoscopic finding

\begin{tabular}{lcccc}
\hline \multirow{2}{*}{ Obstruction level } & Degree of obstruction* & \multicolumn{3}{c}{ Configuration* } \\
\cline { 3 - 4 } & & Anteroposterior diameter & Lateral diameter & Contributing structure \\
\hline Retropalatal & $0 / 1 / 2$ & Palate & LPW & Tonsils \\
Retroglossal & $0 / 1 / 2$ & $0 / 1 / 2$ & $0 / 1 / 2$ & $0 / 1 / 2$ \\
& & Tongue base & LPW & Epiglottis \\
& & $0 / 1 / 2$ & $0 / 1 / 2$ & $0 / 1 / 2$ \\
\hline
\end{tabular}

*degree of obstruction has one number for each structure: $0=$ no obstruction (no vibration), $1=$ partial obstruction (vibration, $50-$ $75 \%), 2=$ complete obstruction (collapse, $>75 \%$ ). LPW: lateral pharyngeal wall

Table 2. DISE finding of obstructive levels and individual obstructive structure (total No. $=75$ )

\begin{tabular}{lrr}
\hline & No. $^{*}$ & $\%$ \\
\hline Obstruction structure of retropalatal level & & \\
Palate & 71 & 94.7 \\
LPW & 57 & 76.0 \\
Tonsils & 20 & 26.7 \\
Palate+tonsils & 1 & 1.3 \\
Palate+LPW & 39 & 52.0 \\
Tonsils+LPW & 0 & 0.0 \\
Palate+LPW+tonsils & 17 & 22.7 \\
Obstruction structure of retroglossal level & & \\
Tongue base & 60 & 80.0 \\
LPW & 51 & 68.0 \\
Epiglottis & 12 & 16.0 \\
Tongue base+epiglottis & 4 & 5.3 \\
Tongue base+LPW & 42 & 56.0 \\
Epiglottis+LPW & 0 & 0.0 \\
Tongue base+LPW+epiglottis & 5 & 6.7 \\
\hline
\end{tabular}

*each level and structure is considered separately, with percentages expressed as a fraction of total number of patients. Percentages sum to greater than $100 \%$ because it was possible for a patient to have more than one structure contributing to airway obstruction. DISE: drug-induced sleep endoscopy, No.: number of patients, LPW: lateral pharyngeal wall

\section{Subgroup}

$\mathrm{BMI}$ 및 기존의 $\mathrm{PSG}$ 결과에 따른 다양한 결과치에 따라 환자군을 세분하고 각 환자군별로 DISE 결과를 비교 분석 하였다. 각각의 환자군별로 세분하는 기준은 $\mathrm{BMI}$ 의 경우 널 리 알려진 비만의 기준에 따라 $25 \mathrm{~kg} / \mathrm{m}^{2}$ 미만인 군과 $25 \mathrm{~kg}$ / $\mathrm{m}^{2}$ 이상인 군으로 분류하였다. ${ }^{10)} \mathrm{PSG}$ 결과치에 따른 환자 군의 구분 역시 기존에 알려진 기준을 사용하였다. AHI에 따 른 OSA의 중등도에 따라 분류한 경우, 5 이상 30 미만인 경 우를 경도-중등도, 30 이상인 경우를 중증 OSA로 분류하였 다. ${ }^{11)}$ 체위 의존성 수면무호흡증(positional dependent OSA, $\mathrm{POSA}$ )과 체위 비의존성 수면무호흡증 환자군(non-positional dependent OSA)으로의 분류는 앙와위 자세시의 AHI(supine $\mathrm{AHI}$ )와 앙와위를 제외한 자세에서의 $\mathrm{AHI}(\mathrm{non}-$ supine $\mathrm{AHI})$ 를 비교하여 supine $\mathrm{AHI} / \mathrm{non}$-supine $\mathrm{AHI}$ 이 2보다 클 때 POSA로 supine AHI/non-supine AHI가 2 이하일 때 non- positional-dependent OSA로 분류하였다. ${ }^{12)}$ 렘수면 의존성 수면무호흡증(rapid eye movement sleep-dependent obstructive sleep apnea, REM OSA)과 렘수면 비의존성 수면무호흡 증(sleep stage non-dependent obstructive sleep apnea, NREM OSA) 환자군으로의 분류는 렘수면시의 AHI(AHIREM)와 비 렘수면시의 AHI(AHINREM)를 비교하여 AHIREM/AHINREM이 2보다 클 때 REM OSA로 AHIREM/AHINREM이 2 이하일 때 NREM OSA로 분류하였다. ${ }^{13)}$

\section{결과 분석 및 통계처리}

위에서 기술한 기준에 따라 측정한 각 결과치에 따라 구분 된 환자군에서 DISE를 통해 관찰된 폐쇄 부위 및 각 구조 물별로 폐쇄 빈도를 파악하여 각 환자군 간의 통계학적 유의 성을 검증하였다. 모든 통계분석은 Statistical Package for the Social Sciences(SPSS version 17.0, SPSS Inc., Chicago, IL, USA)를 이용하여 시행하였으며, 각 군에서 폐쇄 부위 및 각 구 조물별 폐쇄 빈도의 유의성은 카이제곱검정을 이용하여 분석 하였고 통계적 유의 수준은 $p<0.05$ 로 하였다.

\section{결 과}

\section{전체 환자군에서 폐쇄 부위 및 구조물의 빈도}

75 명의 전체 환자군에서 DISE 결과에 따른 각 폐쇄 부위 및 구조물별로 폐쇄 빈도를 파악하였다(Table 2). Retropalatal 부위에서의 각 구조물별 폐쇄 빈도는 연구개(94.7\%)가 가장 흔 한 폐쇄 부위였고 그 다음으로 인두 측벽(76.0\%), 편도(26.7\%) 의 순이었으며, 복합적인 폐쇄시에 연구개와 인두측벽의 폐쇄 가 동반된 경우(52.0\%)가 가장 많았다.

Retroglossal 부위에서의 각 구조물별 폐쇄 빈도는 설근부 (80.0\%)가 가장 흔한 폐쇄 부위였고 그 다음으로 인두 측벽 (68.0\%), 후두개(16.0\%)의 순이었으며, 복합적인 폐쇄시에 설근 부와 인두 측벽의 폐쇄가 동반된 경우(56.0\%)가 가장 많았다.

\section{Subgroup 간 폐쇄 부위 차이}

$\mathrm{BMI}$ 및 $\mathrm{PSG}$ 결과에 따라 분류된 환자군별로 폐쇄 부위 
(retropalatal/retroglossal level)에 따른 폐쇄 빈도를 비교하 였을 때 통계적으로 유의한 결과는 없었다(Table 3).

\section{Subgroup 간 개별적 폐쇄 구조물의 차이}

\section{$\mathrm{BMI}$ 에 따라 분류된 환자군 간의 각 구조물별 폐쇄 빈도}

Retropalatal 부위의 연구개와 인두 측벽이 복합적으로 폐 쇄되는 경우가 $\mathrm{BMI}$ 가 $25 \mathrm{~kg} / \mathrm{m}^{2}$ 이상인 군에서 통계학적으로 유의하게 높았다(Table 4).
$\mathrm{PSG}$ 결과치에 따라 분류된 환자군 간의 각 구조물별 폐쇄 빈도

$\mathrm{AHI}$ 를 사용하여 $\mathrm{OSA}$ 의 중등도에 따라 경도-중등도/중증 $\mathrm{OSA}$ 환자 군으로 나누었을 경우에 각 구조물별 폐쇄 빈도는 retropalatal 부위의 편도의 폐쇄가 중증 OSA 환자군에서 통 계학적으로 유의하게 높았다(Table 5).

$\mathrm{POSA} / \mathrm{non}$-positional-dependent OSA 환자군으로 나누 었을 경우에는 POSA군이 retropalatal 부위에서 인두 측벽의 폐쇄 빈도 및 연구개와 인두 측벽의 복합 폐쇄의 빈도가 유의 하게 높았다(Table 6).

Table 3. Comparison with DISE finding of the obstructive level according to subgroups (total No.=75)

\begin{tabular}{|c|c|c|c|c|c|}
\hline \multicolumn{2}{|c|}{ Obstructive level } & \multicolumn{2}{|c|}{ Retropalatal level } & \multicolumn{2}{|c|}{ Retroglossal level } \\
\hline Subgroups* & No. of each subgroup & No. ${ }^{\dagger}$ & $\%$ & No. ${ }^{\dagger}$ & $\%$ \\
\hline $\mathrm{BMI}<25$ & 34 & 33 & 98.2 & 31 & 91.2 \\
\hline $\mathrm{BMI} \geq 25$ & 41 & 41 & 100.0 & 36 & 87.8 \\
\hline Mild-moderate OSA (AHI) & 55 & 54 & 98.2 & 49 & 89.1 \\
\hline Severe OSA (AHI) & 20 & 20 & 100.0 & 18 & 90.0 \\
\hline Non-positional-dependent OSA & 29 & 29 & 100.0 & 26 & 89.7 \\
\hline Positional-dependent OSA & 46 & 45 & 97.8 & 41 & 89.1 \\
\hline NREM OSA & 36 & 36 & 100.0 & 34 & 94.4 \\
\hline REM OSA & 39 & 38 & 97.4 & 33 & 84.6 \\
\hline
\end{tabular}

* no statistically significant differences in obstruction levels between with each subgroup (chi-squared test, $p>0.05)$, teach level is considered separately, with percentages expressed as a fraction of total number of each subgroup. Percentages sum to greater than $100 \%$ because it was possible for a patient to have more than one level contributing to airway obstruction. DISE: drug-induced sleep endoscopy, No.: number of patients, BMI: body mass index, OSA: obstructive sleep apnea, AHI: apnea-hyponea index, NREM OSA: sleep stage non-dependent obstructive sleep apnea, REM OSA: rapid eye movement sleep-dependent obstructive sleep apnea

Table 4. Correlation between contributing obstructive structure of each obstruction level and BMI (total No.=75)

\begin{tabular}{|c|c|c|c|c|c|}
\hline & \multicolumn{2}{|c|}{$\mathrm{BMI}<25(\mathrm{No} .=34)$} & \multicolumn{2}{|c|}{$\mathrm{BMI} \geq 25(\mathrm{No} .=41)$} & \multirow{2}{*}{$p$ value } \\
\hline & No. ${ }^{\dagger}$ & $\%$ & No. ${ }^{\dagger}$ & $\%$ & \\
\hline \multicolumn{6}{|c|}{ Obstruction structure of retropalatal level } \\
\hline Palate & 32 & 94.1 & 39 & 95.1 & 0.8472 \\
\hline LPW & 23 & 67.6 & 34 & 82.9 & 0.1230 \\
\hline Tonsils & 10 & 29.4 & 10 & 24.4 & 0.6244 \\
\hline Palate+tonsils & 0 & 0.0 & 1 & 2.4 & N/A \\
\hline Palate+LPW* & 12 & 35.3 & 27 & 65.9 & 0.0084 \\
\hline Tonsils+LPW & 0 & 0.0 & 0 & 0.0 & N/A \\
\hline Palate+LPW+tonsils & 10 & 29.4 & 7 & 17.1 & 0.2039 \\
\hline \multicolumn{6}{|c|}{ Obstruction structure of retroglossal level } \\
\hline Tongue base & 25 & 73.5 & 35 & 85.4 & 0.2020 \\
\hline LPW & 24 & 70.6 & 27 & 65.9 & 0.6617 \\
\hline Epiglottis & 6 & 17.6 & 6 & 14.6 & 0.7231 \\
\hline Tongue base + epiglottis & 1 & 2.9 & 3 & 7.3 & N/A \\
\hline Tongue base $+\mathrm{LPW}$ & 19 & 55.9 & 23 & 56.1 & 0.9851 \\
\hline Epiglottis+LPW & 0 & 0.0 & 0 & 0.0 & N/A \\
\hline Tongue base+LPW+epiglottis & 2 & 5.9 & 3 & 7.3 & N/A \\
\hline
\end{tabular}

$* p$ value $<0.05$, teach level and structure is considered separately, with percentages expressed as a fraction of total number of each subgroup. Percentages sum to greater than $100 \%$ because it was possible for a patient to have more than one structure contributing to airway obstruction, ‡chi-squared test. BMI: body mass index, No.: number of patients, LPW: lateral pharyngeal wall, N/ A: not available 
REM OSA 및 NREM OSA 환자군으로 분류한 경우에는 NREM OSA 환자군에서 retropalatal/retroglossal 부위 모두 의 인두 측벽이 통계학적으로 의미 있게 높은 빈도를 보였다 (Table 7).

\section{고 찰}

OSA는 일반인구의 약 2 26\%에서 발생하는 비교적 흔한 질 환이다. ${ }^{14)}$ 수년 동안 반복적인 상기도의 부분 혹은 전체 폐쇄

Table 5. Correlation between contributing obstructive structure of each obstruction level and OSA severity (AHI)(total No.=75)

\begin{tabular}{|c|c|c|c|c|c|}
\hline & \multicolumn{2}{|c|}{ Mild-moderate OSA (No. $=55)$} & \multicolumn{2}{|c|}{ Severe OSA (No. $=20)$} & \multirow{2}{*}{$p$ value } \\
\hline & No. ${ }^{\dagger}$ & $\%$ & No. ${ }^{\dagger}$ & $\%$ & \\
\hline \multicolumn{6}{|c|}{ Obstruction structure of retropalatal level } \\
\hline Palate & 52 & 94.5 & 19 & 95.0 & 0.9382 \\
\hline LPW & 39 & 70.9 & 18 & 90.0 & 0.0869 \\
\hline Tonsils* & 11 & 20.0 & 9 & 45.0 & 0.0304 \\
\hline Palate+tonsils & 0 & 0.0 & 1 & 5.0 & N/A \\
\hline Palate+LPW & 28 & 50.9 & 11 & 55.0 & 0.7538 \\
\hline Tonsils+LPW & 0 & 0.0 & 0 & 0.0 & N/A \\
\hline Palate+LPW+tonsils & 10 & 18.2 & 7 & 35.0 & 0.1240 \\
\hline \multicolumn{6}{|c|}{ Obstruction structure of retroglossal level } \\
\hline Tongue base & 43 & 78.2 & 17 & 85.0 & 0.5139 \\
\hline LPW & 35 & 63.6 & 16 & 80.0 & 0.1791 \\
\hline Epiglottis & 10 & 18.2 & 2 & 10.0 & 0.3927 \\
\hline Tongue base+epiglottis & 4 & 7.3 & 0 & 0.0 & N/A \\
\hline Tongue base $+\mathrm{LPW}$ & 29 & 52.7 & 13 & 65.0 & 0.3437 \\
\hline Epiglottis+LPW & 0 & 0.0 & 0 & 0.0 & N/A \\
\hline Tongue base+LPW+epiglottis & 3 & 5.5 & 2 & 10.0 & N/A \\
\hline
\end{tabular}

*p value $<0.05$, teach level and structure is considered separately, with percentages expressed as a fraction of total number of each subgroup. Percentages sum to greater than $100 \%$ because it was possible for a patient to have more than one structure contributing to airway obstruction, ${ }^{\ddagger}$ chi-squared test. OSA: obstructive sleep apnea, AHI: apnea-hyponea index, No.: number of patients, LPW: lateral pharyngeal wall, N/A: not available

Table 6. Correlation between contributing obstructive structure of each obstruction level and sleep position (total No.=75)

\begin{tabular}{|c|c|c|c|c|c|}
\hline & \multicolumn{2}{|c|}{$\begin{array}{c}\text { Non-positional-dependent } \\
\text { OSA }(\mathrm{No} .=29)\end{array}$} & \multicolumn{2}{|c|}{$\begin{array}{l}\text { Positional-dependent } \\
\text { OSA (No.=46) }\end{array}$} & \multirow[t]{2}{*}{$p$ value $\ddagger$} \\
\hline & No. ${ }^{\dagger}$ & $\%$ & No. $^{+}$ & $\%$ & \\
\hline \multicolumn{6}{|c|}{ Obstruction structure of retropalatal level } \\
\hline Palate & 26 & 89.7 & 45 & 97.8 & 0.1251 \\
\hline LPW* & 17 & 58.6 & 40 & 87.0 & 0.0051 \\
\hline Tonsils & 10 & 34.5 & 10 & 21.7 & 0.2242 \\
\hline Palate+tonsils & 1 & 3.4 & 0 & 0.0 & N/A \\
\hline Palate+LPW* & 9 & 31.0 & 30 & 65.2 & 0.0039 \\
\hline Tonsils+LPW & 0 & 0.0 & 0 & 0.0 & N/A \\
\hline Palate+LPW+tonsils & 7 & 24.1 & 10 & 21.7 & 0.8091 \\
\hline \multicolumn{6}{|c|}{ Obstruction structure of retroglossal level } \\
\hline Tongue base & 24 & 82.8 & 36 & 78.3 & 0.6353 \\
\hline LPW & 17 & 58.6 & 34 & 73.9 & 0.1668 \\
\hline Epiglottis & 5 & 17.2 & 7 & 15.2 & 0.8159 \\
\hline Tongue base+epiglottis & 2 & 6.9 & 2 & 4.3 & N/A \\
\hline Tongue base+LPW & 16 & 55.2 & 26 & 56.5 & 0.9087 \\
\hline Epiglottis+LPW & 0 & 0.0 & 0 & 0.0 & N/A \\
\hline Tongue base+LPW+epiglottis & 1 & 3.4 & 4 & 8.7 & N/A \\
\hline
\end{tabular}


Correlation between Polysomnography and Drug-Induced Sleep Endoscopy in Obstructive Sleep Apnea I Choi JW, et al.

Table 7. Correlation between contributing obstructive structure of each obstruction level and REM sleep (total No.=75)

\begin{tabular}{|c|c|c|c|c|c|}
\hline & \multicolumn{2}{|c|}{ NREM OSA $($ No. $=36)$} & \multicolumn{2}{|c|}{ REM OSA (No.=39) } & \multirow{2}{*}{$p$ value $\ddagger$} \\
\hline & No. ${ }^{+}$ & $\%$ & No. ${ }^{+}$ & $\%$ & \\
\hline \multicolumn{6}{|c|}{ Obstruction structure of retropalatal level } \\
\hline Palate & 34 & 94.4 & 37 & 94.9 & 0.9344 \\
\hline LPW* & 33 & 91.7 & 24 & 61.5 & 0.0023 \\
\hline Tonsils & 11 & 30.6 & 9 & 23.1 & 0.4643 \\
\hline Palate+tonsils & 0 & 0.0 & 1 & 2.6 & N/A \\
\hline Palate+LPW & 22 & 61.1 & 17 & 43.6 & 0.1292 \\
\hline Tonsils+LPW & 0 & 0.0 & 0 & 0.0 & N/A \\
\hline Palate+LPW+tonsils & 10 & 27.8 & 7 & 17.9 & 0.3097 \\
\hline \multicolumn{6}{|c|}{ Obstruction structure of retroglossal level } \\
\hline Tongue base & 30 & 83.3 & 30 & 76.9 & 0.4881 \\
\hline LPW* & 30 & 83.3 & 21 & 53.8 & 0.0062 \\
\hline Epiglottis & 7 & 19.4 & 5 & 12.8 & 0.4344 \\
\hline Tongue base+epiglottis & 1 & 2.8 & 3 & 7.7 & N/A \\
\hline Tongue base+LPW & 22 & 61.1 & 20 & 51.3 & 0.3916 \\
\hline Epiglottis+LPW & 0 & 0.0 & 0 & 0.0 & N/A \\
\hline Tongue base+LPW+epiglottis & 5 & 13.9 & 0 & 0.0 & N/A \\
\hline
\end{tabular}

$* p$ value $<0.05$, teach level and structure is considered separately, with percentages expressed as a fraction of total number of each subgroup. Percentages sum to greater than $100 \%$ because it was possible for a patient to have more than one structure contributing to airway obstruction, ₹chi-squared test. REM: rapid eye movement, No.: number of patients, NREM OSA: sleep stage non-dependent obstructive sleep apnea, REM OSA: REM sleep-dependent obstructive sleep apnea, LPW: lateral pharyngeal wall, N/A: not available

로 무호흡과 저호흡이 일어나며 그로 인한 수면분절과 주간 수면 과다증은 자율신경계의 자극으로 집중력 및 인지 기능 의 저하, 주간 두통이나 고혈압, 부정맥, 야간 심허혈, 심근경 색, 뇌졸중 등의 뇌-심혈관계 질환과 연관성이 있다. ${ }^{15)} \mathrm{OSA}$ 의 진단에는 현재 병력, 신체검사, 영상검사, PSG 등이 이용되 며 그 중 $\mathrm{PSG}$ 가 $\mathrm{OSA}$ 의 중증도의 결정과 기능적 이상을 발견 하는 데 가장 표준의 검사로 알려져 있다. ${ }^{1)}$

'Drug-induced sleep endoscopy'는 검사방법에 내포된 세 가지 특징을 반영하여 명명되었다. 다양한 약물을 이용하여 수면을 유도한다는 점(drug-induced), 정상 수면시와 유사한 상기도 환경을 만든다는 것(sleep), 그 상기도를 내시경을 이 용하여 관찰한다는 점(endoscope)이 그것이다. ${ }^{9)} \mathrm{DISE}$ 로 관 찰된 결과가 실제 증상을 일으키는 폐쇄 부위와의 상관성에 대하여는 이전 연구에서 연구개만 폐쇄가 있는 경우에 다른 부위의 폐쇄가 동반된 경우에 비하여 연구개 수술 후 우수한 결과를 보였다고 보고되었다. ${ }^{16)}$ 또한, DISE 도중에 하악을 전진시켜 보았을 때 나타나는 상기도 폐쇄의 완화 정도는 하악 전진장치(mandibular advancement devise)를 사용하여 나 타난 증상의 호전과 연관이 있었다고 보고되었다. ${ }^{17)}$

하지만 DISE의 검사방법에 내재된 제한점이 있을 수 있다. 가장 중요한 점으로는 DISE에 의한 수면이 정상수면과 같으 냐 하는 문제이다. 이에 대한 연구들이 많이 있었으나 아직 논 란의 여지는 많은 실정이다. 본 연구와 관련된 부분을 살펴보
면, 주로 앙와위에서 시행된 DISE의 소견이 앙와위와 비 앙와 위 전체로 이루어진 실제 수면을 대표하는 PSG 수치들과 차 이가 있을 수 있다는 점이다. 둘째, 미다졸람 등의 약물로 유 도된 수면에서는 3단계 수면과 REM 수면이 출현하지 않는 경우가 많아 실제 폐쇄부위가 관찰되지 않을 수 있어 실제 수 면과는 상이한 결과가 있을 수 있다. ${ }^{18,19)}$ 그러나 기존의 연구 에서 미다졸람으로 유도된 수면은 정상수면의 stage 2 non rapid eye movement와 유사하며, ${ }^{20)}$ 최근 미다졸람을 이용 한 단기 PSG와 fullnight PSG를 비교한 연구에서 두 검사 간 의 수면호흡관련 지수들이 높은 연관성이 있다고 보고되었다. ${ }^{21)}$

셋째, 동일인을 대상으로 실제수면과 약물유도수면시의 내 시경검사 결과가 같다라는 연구는 아직 없는 실정이라는 것이 다. 또한, 타당성 및 신빙성이 있는 일관된 분류방법이 없다는 점도 DISE의 한계점으로 들 수 있다. 이러한 점들은 본 연구의 제한점으로 추후 더 많은 연구가 필요할 것으로 생각된다.

그 외에도 DISE 시행 전에 환자의 자극을 최소화하기 위한 점막 수축제, 마취제를 적신 면구를 이용하여 비강 점막을 수축시킨 점을 들 수 있다. 한 연구에 따르면 양측 비강 내 국 소 마취를 하였을 때 중추성, 폐쇄성 수면무호흡이 모두 증가 하였다고 보고하였고, 이는 수면시에 기류에 대한 비강 내 수 용체의 역할로 생각된다고 하였다. ${ }^{22)}$ 또한, 과도한 진정시에 비 강 내에 삽입된 면구가 흡인의 위험성을 증가시킬 수 있어 주 의가 필요하나 본 연구에서는 발생하지 않았다. 
각 환자 별로 진정에 사용된 방법과 진정의 정도가 동일하지 않다는 점도 제한점으로 들 수 있다. 서로 다른 진정제의 종류 와 투여 방법(propofol and midazolam, bolus and slow gradual titration)은 폐쇄에 기여하는 해부학적 패턴을 변화시킬 수 있다.) Rabelo 등'23) 은 propofol이 렘수면을 감소시키고, 수면 구조를 변화시킨다고 했지만 호흡 패턴과 $\mathrm{AHI}$ 에 현저한 영 향을 미치지는 않는다고 보고했다. 또한, 과도한 진정상태는 상기도 근육의 긴장도를 감소시키고 인두의 폐쇄 압력(closing pressure)을 증가시킨다는 보고도 있다. ${ }^{24)}$ 앞선 여러 연구에서 DISE시에 진정의 방법에 대해 기술하고 있으나 표준화된 방 법은 없는 실정이다. ${ }^{25)}$ 이상적인 진정에 필요한 약물의 농도는 약물에 대한 개인의 감수성에 따라 달라지므로 단계적인 수 면의 유도가 과도한 진정을 피하고 정확한 결과를 얻기 위해 필수적이다.7) 따라서 본 연구에서는 모든 환자에게서 마취과 의사의 감시 하에 수술 방에서 DISE를 진행하였다.

또한 비강 내로의 내시경 삽입시에 발생하는 불편함이 수 면을 방해할 수 있고, 내시경 자체의 부피로 인해 상기도를 좁히거나 주변근육의 역학에 영향을 줄 수 있어 이에 대한 추 가적인 연구가 필요할 것으로 사료된다. 하지만 DISE는 이러 한 제한점에도 불구하고 현재 이용 가능한 진단적 방법들 중 정상 수면상태에 좀 더 가깝게 폐쇄 부위를 관찰할 수 있는 방법 중 하나로 볼 수 있다.

저자들의 연구결과를 종합하면, 첫 번째로 전체 환자군에 서 DISE 결과에 따른 각 폐쇄 부위 및 구조물에 대한 결과 로 보았을 때, 전후 직경을 좁히는 구조물인 연구개 및 설근 부 뿐만 아니라 인두 측벽이 많은 빈도를 보이고 있고, 복합 적인 폐쇄의 경우도 연구개 또는 설근부와 인두 측벽의 폐쇄 가 함께 나타나는 경우가 가장 흔했다(Table 2). 또한, DISE 를 이용하여 상기도 폐쇄 정도를 정량적으로 분석한 기존의 연구에서 측부직경과 전후 직경의 폐쇄 정도의 차이가 유의 성이 없다는 보고가 있었다. ${ }^{26)}$ 이로 미루어 보아 현재 일반적 으로 행해지고 있는 연구개 및 설근부의 전후 직경을 넓히는 데 초점이 맞추어진 치료법에 병행하여 측부 직경에 영향을 미치는 인두 측벽에 대한 좀 더 많은 관심과 연구가 필요할 것 이라 생각된다.

두 번째로 BMI 및 PSG 결과에 따라 분류된 두 군 간에 폐 쇄 부위의 차이는 전반적으로 통계학적 유의성을 보이지 않 았다(Table 3). 따라서, PSG 결과로 각 구조물에 대한 평가 없 이 폐쇄 부위만을 추정하여 양압 호흡기 치료 또는 수술부위 의 결정은 적절치 않아 보인다.

각 구조물에 대한 분석 결과, 비만한 환자, POSA 환자, NREM OSA 환자에서 전반적으로 인두 측벽에 의한 상기도 폐쇄 빈도가 더 높았고, 중증 OSA 환자에서도 인두 측벽에
의한 상기도 폐쇄 빈도는 높았으나 통계적으로 의미 있는 결 과는 보이지 않았다. 또한 복합적인 구조물에 의한 폐쇄일 경 우에도 연구개 또는 설근부와 인두 측벽이 폐쇄에 기여하는 빈도가 높은 것으로 보인다(Table 4-7). 따라서, 위와 같은 결과를 보이는 OSA 환자에서 수술적 치료시에 인두 측벽의 교정에 더욱 관심을 가져야 할 것이다. OSA의 수술적 치료에 반응이 없는 환자들을 분석한 이전의 연구들에서 연구개 부 위의 완전 또는 부분적인 환상형 폐쇄와 설근부 또는 후두 개로 인한 전후 직경의 완전 폐쇄가 의미 있게 높았다고 하 였고, ${ }^{7,27)}$ 인두 측벽과 성문 상부의 폐쇄가 수술 실패와 연관 이 있다는 보고도 있어 본 연구와 부합되는 결과를 보이고 있다. ${ }^{28)}$

그 외에도 비만한 환자의 경우 통계학적으로 유의하진 않았 지만 설근부의 폐쇄 빈도가 높은 경향을 보였으며(Table 4), 이는 해부학적으로 설근부의 지방 분포 비가 다른 상기도 부 위에 비해 높아 비만에 설근부가 영향을 많이 받는 것으로 설 명될 수 있다. ${ }^{29)}$ 따라서, 비만한 환자의 경우 설근부의 교정에 관심을 가져야 할 것으로 사료된다.

편도의 경우에는 중증 OSA 환자군에서 폐쇄 빈도가 높게 나타났고(Table 5), 이에 따라 저자들은 심한 OSA 환자에서 수술적 치료를 시행할 경우 편도절제술을 함께 시행하는 것이 도움이 될 것이라고 생각한다.

또한 해부학적으로는 연구개, 설근부, 후두개와 같은 전후 직경을 좁히는 구조물들이 체위 의존성 수면무호흡증 유발하 는데 기여도가 클 것으로 예상할 수 있으나 실제 결과는 상기 구조물들에서는 통계학적 유의성을 보이지 않았고 오히려 인 두 측벽에서 차이를 보였다(Table 6). 이는 설근부와 후두개의 폐쇄가 체위 의존성 수면무호흡증 환자 군에서 의미 있게 높 았다는 이전의 연구결과와 상반되는 것으로 수면구조와 상기 도의 해부학적 구조에 대한 연구가 필요할 것이다.)

따라서, DISE와 PSG 결과를 종합해서 분석할 경우 OSA 환자에 대한 치료 방침을 수립하고 치료 효과를 예측하는 데 도움이 될 수 있을 것으로 생각된다. 향후 폐쇄 부위 평가를 위한 일관적인 분류 방법 및 폐쇄 부위에 따른 치료 후 이에 대한 추적 관찰을 통한 각 치료 방법의 효과에 대한 연구가 필 요할 것으로 사료된다.

\section{REFERENCES}

1) Min YG, Jung HW, Kim IY, Rhee CS, Jang YJ, Shim YS, et al. Evaluation of polysomnographic findings on diagnosis of OSA. Korean J Otolaryngol-Head Neck Surg 1992;35(1):88-94.

2) Hong SK, Park MH, Lee IK. Long-term outcome of uvulopalatopharyngoplasty in obstructive sleep apnea syndrome patients: comparison between changes of subjective symptoms and objective indexes including respiratory and sleep parameters. 
Korean J Otolaryngol-Head Neck Surg 1997;40(9):1313-8.

3) Park YH, Park SY, Park HS, Kim JM, Yoon HR. The prognostic factors of uvulopalatopharyngoplasty in obstructive sleep apnea. Korean J Otolaryngol-Head Neck Surg 1998;41(2):213-7.

4) Sher AE, Schechtman KB, Piccirillo JF. The efficacy of surgical modifications of the upper airway in adults with obstructive sleep apnea syndrome. Sleep 1996;19(2):156-77.

5) Croft CB, Pringle M. Sleep nasendoscopy: a technique of assessment in snoring and obstructive sleep apnoea. Clin Otolaryngol Allied Sci 1991;16(5):504-9.

6) den Herder C, van Tinteren H, de Vries N. Sleep endoscopy versus modified Mallampati score in sleep apnea and snoring. Laryngoscope 2005;115(4):735-9.

7) Ravesloot MJ, de Vries N. One hundred consecutive patients undergoing drug-induced sleep endoscopy: results and evaluation. Laryngoscope 2011;121(12):2710-6.

8) Hernández-Gancedo C, Pestaña D, Peña N, Royo C, Pérez-Chrzanowska $\mathrm{H}$, Criado A. Monitoring sedation in critically ill patients: bispectral index, Ramsay and observer scales. Eur J Anaesthesiol 2006;23(8): 649-53.

9) Kezirian EJ, Hohenhorst W, de Vries N. Drug-induced sleep endoscopy: the VOTE classification. Eur Arch Otorhinolaryngol 2011;268(8): 1233-6.

10) WHO Expert Consultation. Appropriate body-mass index for Asian populations and its implications for policy and intervention strategies. Lancet 2004;363(9403):157-63.

11) American Sleep Disorders Association. The International Classification of Sleep Disorders: revised: Diagnostic and Coding Manual. Rochester, MN: American Sleep Disorders Association; 1997.

12) Oksenberg A, Silverberg DS, Arons E, Radwan H. Positional vs nonpositional obstructive sleep apnea patients: anthropomorphic, nocturnal polysomnographic, and multiple sleep latency test data. Chest 1997;112(3):629-39.

13) Haba-Rubio J, Janssens JP, Rochat T, Sforza E. Rapid eye movementrelated disordered breathing: clinical and polysomnographic features. Chest 2005;128(5):3350-7.

14) Kryger MH. Diagnosis and management of sleep apnea syndrome. Clin Cornerstone 2000;2(5):39-47.

15) Schäfer H, Koehler U, Ploch T, Peter JH. Sleep-related myocardial ischemia and sleep structure in patients with obstructive sleep apnea and coronary heart disease. Chest 1997;111(2):387-93.
16) Iwanaga K, Hasegawa K, Shibata N, Kawakatsu K, Akita Y, Suzuki $\mathrm{K}$, et al. Endoscopic examination of obstructive sleep apnea syndrome patients during drug-induced sleep. Acta Otolaryngol Suppl 2003; (550):36-40.

17) Johal A, Battagel JM, Kotecha BT. Sleep nasendoscopy: a diagnostic tool for predicting treatment success with mandibular advancement splints in obstructive sleep apnoea. Eur J Orthod 2005;27(6):607-14.

18) Moos DD. Obstructive sleep apnea and sedation in the endoscopy suite. Gastroenterol Nurs 2006;29(6):456-63; quiz 464-5.

19) Stuck BA, Maurer JT. Airway evaluation in obstructive sleep apnea. Sleep Med Rev 2008;12(6):411-36.

20) Won TB. Contemporary methods of upper airway evaluation in obstructive sleep apnea patients. Korean J Otorhinolaryngol-Head Neck Surg 2013;56(1):7-13.

21) Gregório MG, Jacomelli M, Inoue $D$, Genta PR, de Figueiredo AC, Lorenzi-Filho G. Comparison of full versus short induced-sleep polysomnography for the diagnosis of sleep apnea. Laryngoscope 2011;121(5):1098-103.

22) White DP, Cadieux RJ, Lombard RM, Bixler EO, Kales A, Zwillich $\mathrm{CW}$. The effects of nasal anesthesia on breathing during sleep. Am Rev Respir Dis 1985;132(5):972-5.

23) Rabelo FA, Braga A, Küpper DS, De Oliveira JA, Lopes FM, de Lima Mattos PL, et al. Propofol-induced sleep: polysomnographic evaluation of patients with obstructive sleep apnea and controls. Otolaryngol Head Neck Surg 2010;142(2):218-24.

24) Rodriguez-Bruno K, Goldberg AN, McCulloch CE, Kezirian EJ. Test-retest reliability of drug-induced sleep endoscopy. Otolaryngol Head Neck Surg 2009;140(5):646-51.

25) Berry S, Roblin G, Williams A, Watkins A, Whittet HB. Validity of sleep nasendoscopy in the investigation of sleep related breathing disorders. Laryngoscope 2005;115(3):538-40.

26) Borek RC, Thaler ER, Kim C, Jackson N, Mandel JE, Schwab RJ. Quantitative airway analysis during drug-induced sleep endoscopy for evaluation of sleep apnea. Laryngoscope 2012;122(11):2592-9.

27) Koutsourelakis I, Safiruddin F, Ravesloot M, Zakynthinos S, de Vries N. Surgery for obstructive sleep apnea: sleep endoscopy determinants of outcome. Laryngoscope 2012;122(11):2587-91.

28) Soares D, Sinawe H, Folbe AJ, Yoo G, Badr S, Rowley JA, et al. Lateral oropharyngeal wall and supraglottic airway collapse associated with failure in sleep apnea surgery. Laryngoscope 2012;122(2):473-9.

29) Nashi N, Kang S, Barkdull GC, Lucas J, Davidson TM. Lingual fat at autopsy. Laryngoscope 2007;117(8):1467-73. 